\section{Suicidal Ideation}

Glenn A. Ashkanazi

Clinical \& Health Psychology Clinic, College of Public Health and Health Professions, University of Florida, Gainesville, FL, USA

\section{Synonyms}

Suicidal thinking

\section{Definition}

Includes thoughts about intentionally taking one's own life and can range from a fleeting consideration to the creation of detailed suicidal plan. One study found a substantial proportion of post-TBI participants had experienced suicidal ideation $(23 \%)$ post-injury, while a smaller proportion $(18 \%)$ had made a suicide attempt post-injury.
A more recent study found similar percentages $(25 \%)$ between time of injury and 1-year postTBI with strong predictors including history of prior suicide attempt, history of bipolar disorder, and having less than high school education.

\section{References and Readings}

Klonsky, E., May, A., \& Saffer, B. (2016). Suicide, suicide attempts, and suicidal ideation. Annual Review of Clinical Psychology, 12, 1-542.

Mackelprang, J., Bombardier, C., Fann, J., Temkin, N., Barber, J., \& Dikmen, S. (2013). Rates and predictors of suicidal ideation during the first year after traumatic brain injury. American Journal of Public Health, 104 (7), e100-e107. (July 1, 2014).

Simpson, G. K. PhD, \& Brenner, L. A. PhD (eds.). (2011). Perspectives on suicide and traumatic brain injury (entire issue). Journal of Head Trauma Rehabilitation, 26(4), 241.

Simpson, G., \& Tate, R. (2002). Suicidality after traumatic brain injury: Demographic, injury and clinical correlates. Psychological Medicine, 12(4), 687-697. 